\title{
Improved $n$-butanol production by a non-acetone producing Clostridium pasteurianum DSMZ 525 in mixed substrate fermentation
}

\author{
Wael Sabra • C. Groeger • P. N. Sharma • An-Ping Zeng
}

Received: 17 December 2013 /Revised: 30 January 2014 / Accepted: 2 February 2014 / Published online: 2 March 2014

(C) The Author(s) 2014. This article is published with open access at Springerlink.com

\begin{abstract}
The kinetics of growth, acid and solvent production in batch culture of Clostridium pasteurianum DSMZ 525 were examined in mixed or mono-substrate fermentations. In $\mathrm{pH}$-uncontrolled batch cultures, the addition of butyric acid or glucose significantly enhanced $n$-butanol production and the ratio of butanol/1,3-propanediol. In $\mathrm{pH}$-controlled batch culture at $\mathrm{pH}=6$, butyric acid addition had a negative effect on growth and did not lead to a higher $n$-butanol productivity. On the other hand, mixed substrate fermentation using glucose and glycerol enhanced the growth and acid production significantly. Glucose limitation in the mixed substrate fermentation led to the reduction or inhibition of the glycerol consumption by the growing bacteria. Therefore, for the optimal growth and $n$-butanol production by $C$. pasteurianum, a limitation of either substrate should be avoided. Under optimized batch conditions, $n$-butanol concentration and maximum productivity achieved were $21 \mathrm{~g} / \mathrm{L}$, and $0.96 \mathrm{~g} / \mathrm{L} \times \mathrm{h}$, respectively. In comparison, mixed substrate fermentation using biomass hydrolysate and glycerol gave a $n$-butanol concentration of $17 \mathrm{~g} /$ $\mathrm{L}$ with a maximum productivity of $1.1 \mathrm{~g} / \mathrm{L} \times \mathrm{h}$. In terms of productivity and final $n$-butanol concentration, the results demonstrated that $C$. pasteurianum DSMZ 525 is well suitable for $n$-butanol production from mixed substrates of biomass hydrolysate and glycerol and represents an alternative promising production strain.
\end{abstract}

W. Sabra $(\varangle) \cdot$ C. Groeger $\cdot$ P. N. Sharma $\cdot$ A.-P. Zeng $(\bowtie)$ Institute of Bioprocess and Biosystems Engineering, Hamburg University of Technology, Denickestr.15, 21073 Hamburg, Germany e-mail: Wael.Sabra@tuhh.de e-mail: AZE@TUHH.de

W. Sabra

Microbiology Department, Faculty of Science, Alexandria

University, Alexandria, Egypt
Keywords Butanol production · Clostridium pasteurianum . ABE fermentation $\cdot$ Mixed substrate fermentation

\section{Introduction}

Before the 1950s, acetone-butanol-ethanol (ABE) fermentations using Clostridia ranked second to ethanol in importance and scale of bioproduction processes. The ABE fermentation declined or was even shut down because of increased substrate costs and the availability of much cheaper, petrochemically derived butanol (Zverlov et al. 2006). However, in recent years, there has been a renewed interest in this fermentation, which has led to a large number of studies on the metabolism and genetics of solventogenic Clostridia and on the improvement of fermentation and product recovery technologies (Garcia et al. 2011). Currently, there are still three major hurdles for fermentative $n$-butanol to compete with the petroleum-based one (Biebl 2001; Jang et al. 2012; Lee et al. 2012; Tracy 2012). These include (1) high cost of substrates: molasses, as typically used as a substrate in the past, may account for about $50 \%$ of the final cost of the product (Vandecasteele and Marchal 1993); (2) low final product concentrations due to limited bacterial tolerance and (3) high product recovery costs due to the low concentration of $n$ butanol produced. Recent interest in the production of biobutanol from biomass has led to the reexamination of the $n$-butanol fermentation. Advances in strain development, integrated fermentation and in situ product removal processes have resulted in a dramatic reduction of process streams, reduced $n$-butanol toxicity to the fermenting microorganisms, improved substrate utilization and overall bioreactor performance. Therefore, a possible reintroduction of large-scale ABE fermentation appears increasingly feasible (Jesse et al. 2002; Qureshi et al. 2006, 2007, 2008; Lee et al. 2012; Liu et al. 2013). Nevertheless, the cost of $n$-butanol recovery still 
remains high. Significant energy savings can be achieved if the concentration of $n$-butanol in the fermentation broth is increased.

In order to realize industrial-scale $n$-butanol fermentation, an efficient process based on a high-performance $n$-butanol producer utilizing inexpensive carbon substrate such as biomass hydrolysate $(\mathrm{BH})$ from cellulosic materials is desired. Beside, glycerol as a byproduct from biodiesel production has recently also attracted much attention as a potential substrate for bio-based production of chemicals and fuels. Their abundance and cost competitiveness make both substrates excellent candidates for $n$-butanol production. The mostly studied microorganism for biological production of $n$-butanol is Clostridium acetobutylicum, and ABE fermentation by using this microorganism was the basis for $n$-butanol production on an industrial scale for a long period of time. However, C. acetobutylicum is unable to grow on glycerol as a sole carbon source, since it cannot efficiently reoxidize the excess NADH generated in glycerol catabolism (Patakova et al. 2013). Clostridium pasteurianum, on the other hand, is known as a potentially promising producer of $n$-butanol. This microorganism normally does not produce acetone and ethanol, but organic acids such as acetic and butyric acids as major fermentation products from sugars. It can also produce 1,3propanediol (1,3-PDO) when grown on glycerol (Biebl 2001; Jensen et al. 2012a, b). Biebl (2001) first reported the production of $17 \mathrm{~g} / \mathrm{L} n$-butanol in batch cultures with C. pasteurianum grown in semi-synthetic media containing glycerol as the sole carbon source. However, a great variation in the product formation was observed in batch cultures: i.e. either $n$-butanol or 1,3-PDO could be produced as the major product under equal or slightly different conditions. A weak pathway regulation and the existence of multiplicity have been assumed by Biebl (2001). Recently, Moon et al. (2011) and Khanna et al. (2013a) optimized the medium compositions to favour $n$-butanol or 1,3-PDO production in free and immobilized cultures of $C$. pasteurianum, respectively. Kao et al. (2012) studied the co-fermentation of glucose and glycerol by using the strain $C$. pasteurianum $\mathrm{CH} 4$. The $n$-butanol production was increased from $11 \mathrm{~g} / \mathrm{L}$ in a medium containing sole glycerol to $13.3 \mathrm{~g} / \mathrm{L}$ in a medium containing both glucose and glycerol. The maximum $n$-butanol productivity obtained under optimal conditions was $0.28 \mathrm{~g} / \mathrm{L} \times \mathrm{h}$ in this cofermentation process. The productivity can be significantly improved by in situ $n$-butanol removal, as demonstrated by Jensen et al. (2012a, b) using gas stripping to remove $n$ butanol in glycerol fermentation with C. pasteurianum DSMZ 525 . With gas stripping during the fermentation, these authors could achieve $n$-butanol productivity as high as $1.3 \mathrm{~g} / \mathrm{L} \times \mathrm{h}$. Using the same $C$. pasteurianum strain (DSMZ 525) but without the in situ $n$-butanol removal, we report in this work an optimized $n$-butanol production process using mixed substrates. It is shown that glucose as a co-substrate in the glycerol fermentation with $C$. pasteurianum can significantly enhance the cell growth and consequently the $n$-butanol productivity. A maximum productivity of $0.96 \mathrm{~g} / \mathrm{L} \times \mathrm{h}$ and a final $n$-butanol concentration of $21.5 \mathrm{~g} / \mathrm{L}$ were reached. This represents the highest $n$-butanol titer ever reached in a normal suspension culture of Clostridia. The use of BH was also evaluated in the co-substrate bioprocess for $n$-butanol production.

\section{Materials and methods}

Microorganism and medium

C. pasteurianum DSMZ 525 was cultivated anaerobically at $35{ }^{\circ} \mathrm{C}$ without shaking. Stock cultures were maintained on Reinforced Clostridial Medium (RCM, Oxoid Deutschland $\mathrm{GmbH}$, Wesel, Germany) and preserved using glycerol $20 \%$ $(v / v)$ at $-80^{\circ} \mathrm{C}$. Liquid cultivation was done in serum bottles containing either the RCM or the production media. Resazurin (7-hydroxy-10-oxidophenoxazin-10-ium-3-one) was added at a concentration of $1 \mathrm{mg} / \mathrm{L}$ as a redox indicator for anaerobiosis.

RCM inoculated from a cryoculture was left to grow at $35^{\circ} \mathrm{C}$ for $18-20 \mathrm{~h}$ and then used as inocula for the production medium. The standard production medium for batch cultures contained the following ingredients in $1 \mathrm{~L}$ of distilled water (modified from Biebl 2001): glycerol, varied; glucose, varied; $\mathrm{K}_{2} \mathrm{HPO}_{4}, 0.5 \mathrm{~g} ; \mathrm{KH}_{2} \mathrm{PO}_{4}, 0.5 \mathrm{~g}, \mathrm{MgSO}_{4} \cdot 7 \mathrm{H}_{2} 0,0.2 \mathrm{~g}$; $\left(\mathrm{NH}_{4}\right)_{2} \mathrm{SO}_{4}, 5 \mathrm{~g} ; \mathrm{CaCl}_{2} 2 \mathrm{H}_{2} \mathrm{O}, 0.02 \mathrm{~g}, \mathrm{FeSO}_{4} 7 \mathrm{H}_{2} \mathrm{O}, 0.01 \mathrm{~g}$; cysteine $\mathrm{HCl}, 0.3 \mathrm{~g}$; resarzurin, $0.005 \mathrm{~g} ; 2 \mathrm{~mL}$ of trace element solution SL7 and $1 \mathrm{~g}$ yeast extract. In anaerobic bottles, the medium $\mathrm{pH}$ was adjusted to 7 with $1 \mathrm{~N} \mathrm{NaOH}$ and $\mathrm{CaCO}_{3}$ was added at a concentration of $2 \mathrm{~g} / \mathrm{L}$.

Uncontrolled batch experiments were done using $100-\mathrm{mL}$ serum bottles filled with $50 \mathrm{~mL}$ medium containing $25 \mathrm{~g} / \mathrm{L}$ glycerol and the different co-substrates. The $\mathrm{pH}$ was adjusted and the medium was boiled and cooled under nitrogen to ensure anaerobic condition and autoclaved. Glucose was autoclaved separately in anaerobic bottles with nitrogen as headspace and added after autoclaving. Experiments were conducted in triplicate, and culture was inoculated with $5 \%$ $(v / v)$ of RCM growing cultures and incubated for 5 days.

Batch and fed-batch cultivations were carried out in a $\mathrm{pH}-$ controlled 2-L stirred tank bioreactor (Bioengineering) with a working volume of $1.5 \mathrm{~L}$. After sterilization, the medium in the bioreactor was flushed with sterile oxygen-free nitrogen gas until room temperature was reached. Glucose was autoclaved separately and was added together with the sterile cystein $\mathrm{HCl}$ and $\mathrm{FeSO}_{4}$ solution and inoculated immediately. Spruce BH (Borregard, Norway) was also used in co-substrate fermentation with glycerol. The enzymatic hydrolysis of spruce was done without buffer. The hydrolysate was then 
heated at $80^{\circ} \mathrm{C}$ for $15-20 \mathrm{~min}$ to inactivate the enzymes. The supernatant was removed and filtered with a centrifuge with filter bag. The sample was then concentrated by vacuum evaporation at $60^{\circ} \mathrm{C}$. The concentrated hydrolysate contained $550 \mathrm{~g} / \mathrm{L}$ glucose and $35 \mathrm{~g} / \mathrm{L}$ xylose and was autoclaved separately. Flushing with nitrogen was stopped after inoculation, and the bacteria were grown under their own produced gases. The $\mathrm{pH}$ was adjusted to 6 by automatic addition of $5 \mathrm{~N}$ $\mathrm{KOH}$.

\section{Analytical methods}

Cell concentration was measured turbidometrically at $600 \mathrm{~nm}$ and correlated with cell dry weight determined directly. In the cell-free supernatants, the concentrations of glucose, glycerol, butanol, 1,3-PDO, ethanol, acetic, butyric and lactic acids were determined by HPLC using an Aminex HPX-87H column $(300 \times 7.8 \mathrm{~mm})$ and detection was assessed by refractive index and ultraviolet detectors. The HPLC operating conditions were as follows: mobile phase, $5 \mathrm{mM} \mathrm{H}_{2} \mathrm{SO}_{4}$; flow rate, $0.6 \mathrm{~mL} / \mathrm{min}$ and temperature, $60{ }^{\circ} \mathrm{C}$. Acetone was detected with an Agilent headspace gas chromatography $(6,890 \mathrm{~N})$ equipped with a Stabiwax DA capillary column $(60 \mathrm{~m} \times$ $320 \mu \mathrm{m})$ and a FID detector. Helium was used as a carrier gas $(100 \mathrm{kPa})$. The analysis was run at $50{ }^{\circ} \mathrm{C}$ for $1 \mathrm{~min}$ and then $15^{\circ} \mathrm{C} / \mathrm{min}$ till $200{ }^{\circ} \mathrm{C}$ for $5 \mathrm{~min}$.

\section{Results}

$\mathrm{pH}$-uncontrolled cultures of C. pasteurianum with different co-substrates

Results of growth and product formation of $C$. pasteurianum in anaerobic bottles supplemented with various combinations of co-substrates are presented in Fig. 1. The $\mathrm{pH}$ of the medium was adjusted to $\mathrm{pH} \mathrm{7,} \mathrm{and} \mathrm{stock} \mathrm{solutions} \mathrm{of} \mathrm{organic} \mathrm{acids}$ were neutralized ( $\mathrm{pH} 7)$, sterile filtered and added to the anaerobic bottles at different concentrations. It was found that the addition of increasing amounts of organic acids, and especially, butyric acid enhanced the production of butanol. A maximum of $7 \mathrm{~g} / \mathrm{L} n$-butanol was produced by the strain grown on glycerol supplemented with $5 \mathrm{~g} / \mathrm{L}$ butyric acid, compared to $1.85 \mathrm{~g} / \mathrm{L} n$-butanol in mono-substrate fermentation. The butanol/1,3-PDO ratio also increased steadily with increasing butyric acid concentration. Butyric acid concentrations above $5 \mathrm{~g} / \mathrm{L}$ resulted in diminished cell growth. On the other hand, in bottles with glucose or blend of glucose and glycerol, acid production increased significantly and was five to eightfold higher compared to growth on glycerol. Since no natural pathway exists for a direct production of 1,3-PDO from glucose, the butanol/1,3-PDO ratio increased significantly in bottles with co-substrates. The gases produced during bacterial growth resulted in increased pressure in the anaerobic bottles. Under these conditions, the glycerol initially added $(25 \mathrm{~g} / \mathrm{L})$ was never completely consumed even after $110 \mathrm{~h}$.

Butyrate addition and $n$-butanol production in $\mathrm{pH}$-controlled bioreactors

The co-substrate fermentation with $C$. pasteurianum was further studied in controlled bioreactor to maximize the $n$-butanol production. In a $\mathrm{pH}$-controlled batch culture with a medium containing glycerol, butyric acid was added either gradually or at different growth phases of the fermentation. As a control, C. pasteurianum was cultivated on glycerol as the sole carbon source. In all fermentations, the $\mathrm{pH}$ was regulated at 6 by the addition of $5 \mathrm{~N} \mathrm{KOH}$.

As can be seen in Fig. 2a, without butyrate addition, the major products formed during glycerol fermentation were $n$ butanol $(15.2 \mathrm{~g} / \mathrm{L})$ and 1,3-PDO $(6.2 \mathrm{~g} / \mathrm{L})$. The production of butyric and acetic acids was negligible during the whole fermentation and did not exceed $0.5 \mathrm{~g} / \mathrm{L}$. At slightly acidic $\mathrm{pH}$ of 6, butyric acid addition resulted in a slower growth rate. In fact, the addition of butyric acid at the beginning of the batch culture extended the lag period significantly and no growth was initiated if the initial $\mathrm{pH}$ was lower than 5.5 (data not shown). Butyric acid was then added either continuously (Fig. 2b) or at the mid and late logarithmic growth phases (growth OD of 6 and 9, respectively).

Generally, the various strategies used to add butyric acid into the fermentation of glycerol did not result in an increase of $n$-butanol production. Moreover, the utilization of butyric acid as a co-substrate depends on the growth phase. Whereas acid addition at the late logarithmic phase (at biomass concentration of $3.1 \mathrm{~g} / \mathrm{L}$ ) stopped the bacterial metabolism and no butyrate consumption or $n$-butanol production occurred, the gradual addition during the fermentation (Fig. 2b) or at the mid logarithmic phase (at biomass concentration of $2.1 \mathrm{~g} / \mathrm{L}$, data not shown) resulted in significant acid consumption and a comparable $n$-butanol concentration as the control (Fig. 2a). More significantly, the addition of butyric acid had an influence on the 1,3-PDO formation and consequently on the butanol/1,3-PDO ratio (Fig. 3). Previously, we showed that a $\mathrm{pH}$ shift to the acidic range stopped 1,3-PDO production and increased the butanol/1,3-PDO ratio significantly (data not shown). A similar effect is demonstrated here with butyric acid addition, and the earlier the addition of butyric acid to the culture media, the less the 1,3-PDO is formed and the higher the butanol/1,3-PDO ratio that could be achieved (Fig. 3).

The effect of glucose as co-substrate on bacterial growth and acid production

As shown in Fig. 1, mixed substrate fermentation with glucose in anaerobic bottles increased $n$-butanol production 
Fig. 1 The effects of acetic $(H A c)$, butyric acid $(H B c)$ and glucose addition on butanol $(\mathrm{BuOH})$ formation from glycerol

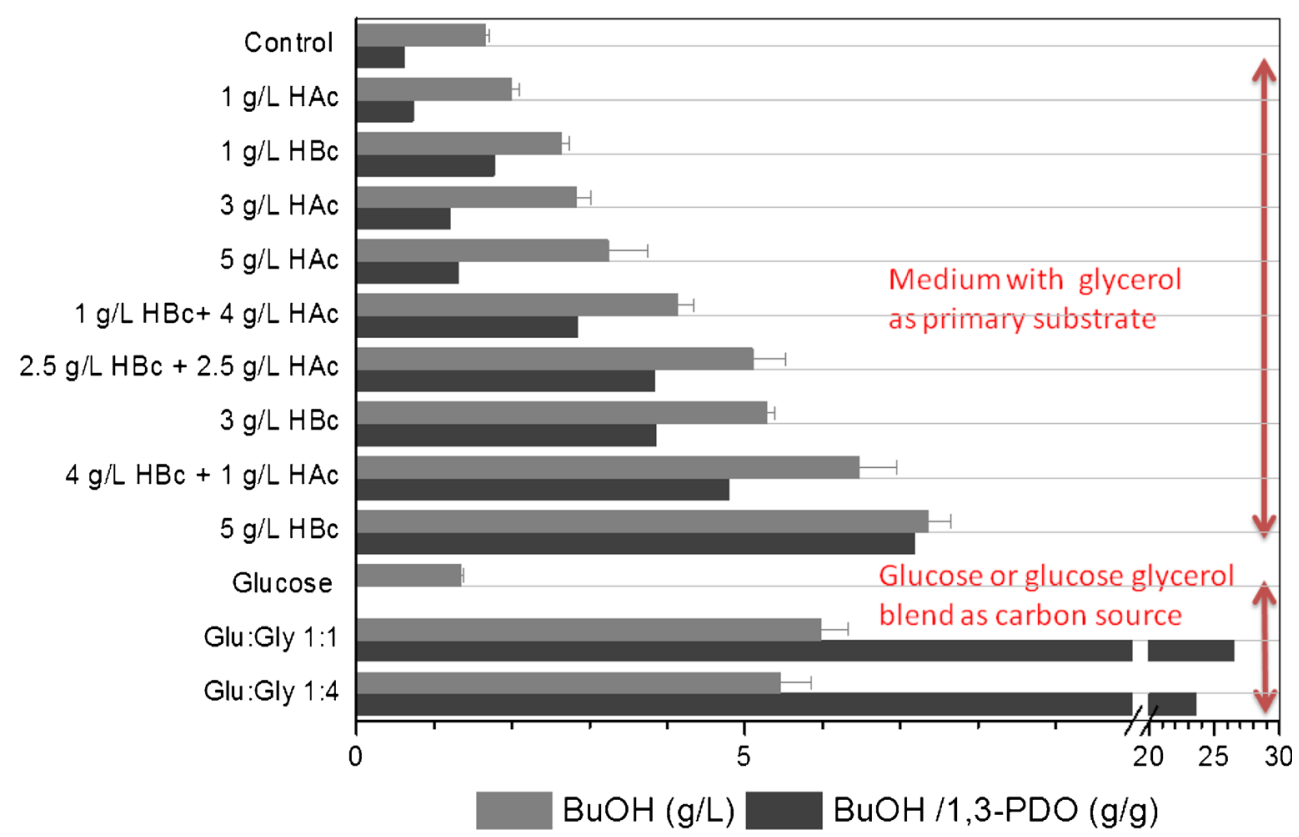

significantly. Moreover, since no natural pathway exist for 1,3-PDO synthesis from glucose, the butanol/1,3-PDO ratio

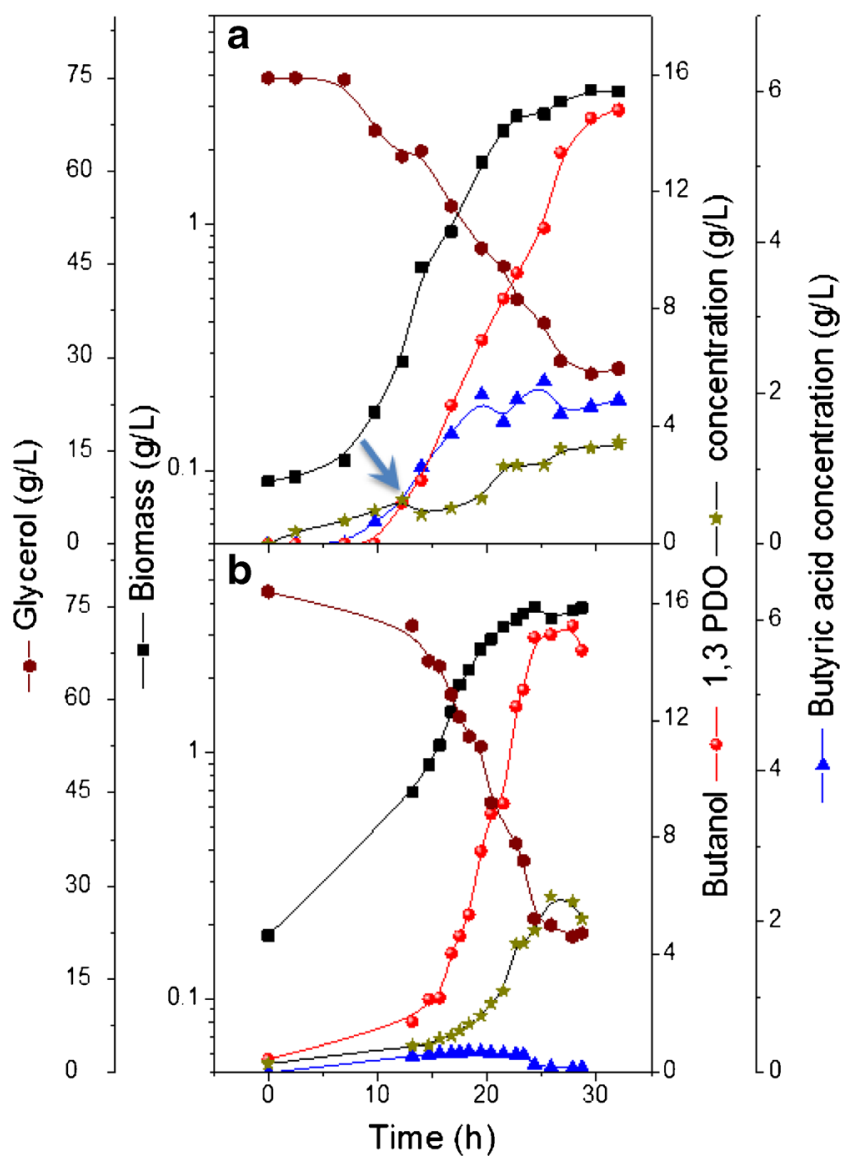

Fig. 2 Growth, butanol and 1,3-PDO production in batch cultures of C. pasteurianum DSMZ 525 grown on glycerol fed with butyrate (a) or on glycerol (b). Arrow shows the beginning of the continuous butyrate addition increased drastically in such anaerobic bottles. Therefore, in $\mathrm{pH}$-controlled bioreactors, we tested the effect of glucose addition as co-substrate in different ratios (glucose-to-glycerol ratio, 1:0, 1:1, 4:1 and 1:4). All the co-substrate fermentations were inoculated with cells grown on glycerol. Generally, increasing the glucose fraction in the co-substrate fermentation increased biomass and acid production significantly as can be seen from the base consumption in the $\mathrm{pH}$-controlled experiments. The specific growth rate of the bacterium grown in the presence of glucose was generally higher and reached $0.25 \mathrm{~h}^{-1}$ ( \pm 0.02 at the different co-substrate fermentations) compared to $0.19 \mathrm{~h}^{-1}$ on pure glycerol.

Growth on glucose as the sole carbon source is shown in Fig. 4. Being a classical acid producer, $C$. pasteurianum was known to ferment carbohydrates to butyrate, acetate, $\mathrm{CO}_{2}$ and $\mathrm{H}_{2}$ (Dabrock et al. 1992). A maximum $n$-butanol concentration of $6.9 \mathrm{~g} / \mathrm{L}$ was obtained, and most of the glucose was directed for the production of organic acids. Moreover, unlike glycerol fermentation, the two phases, acidogenesis and solventogenesis, were clearly separated during glucose fermentation (Fig. 4).

Different ratios of glucose and glycerol for the optimized $n$-butanol production in mixed substrate fermentation

Since glycerol is the natural substrate for 1,3-PDO formation in $C$. pasteurianum, the 1,3-PDO formation increased with increasing glycerol portion in the co-substrate fermentation (the 1,3-PDO production increased from 0 to $2.2,5.2$ and $10.3 \mathrm{~g} / \mathrm{L}$ at glucose-to-glycerol ratio of 1:0, 4:1, 1:1 and 1:4). Moreover, the typical fermentation profile with two phases, namely, acidogenesis and solventogenesis observed 
Fig. 3 Comparison between concentrations of butanol, 1,3PDO and their ratio as affected by the addition of butyric acid in $\mathrm{pH}$ controlled batch cultures

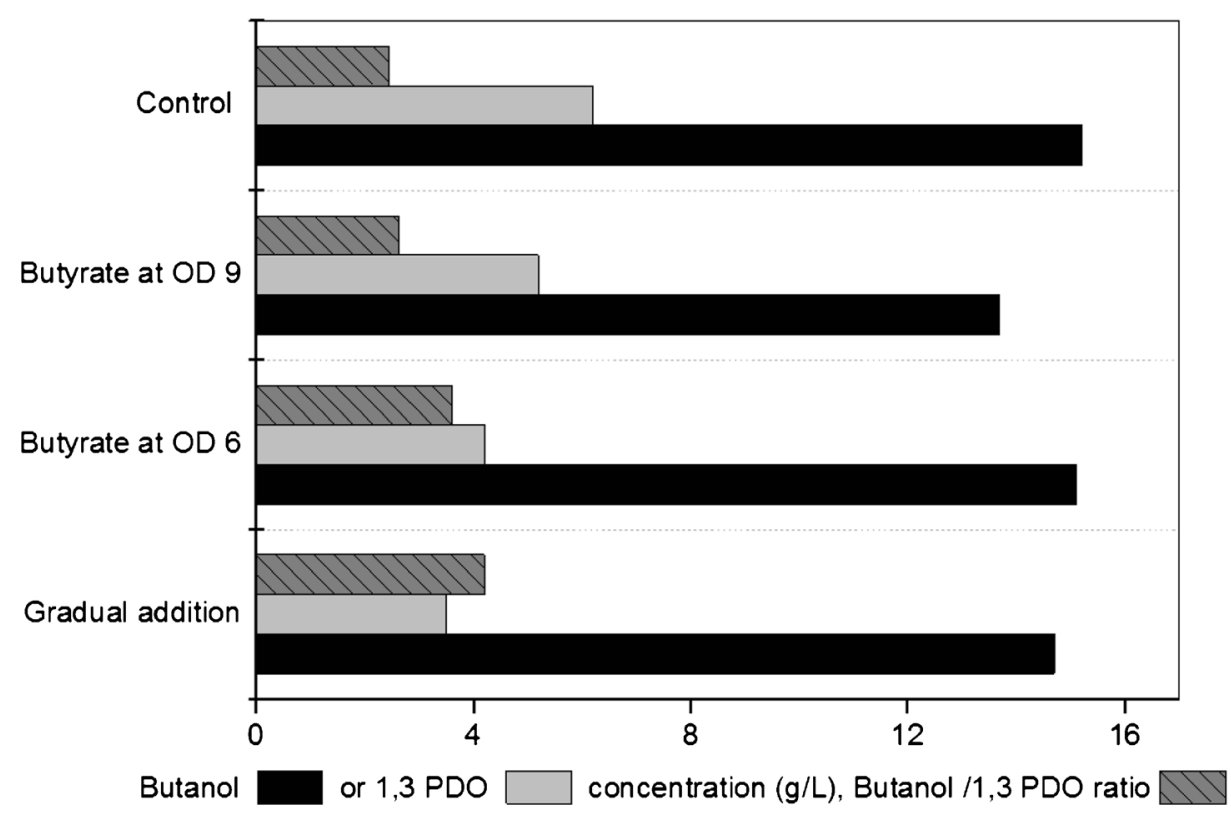

$(g / g)$ in mono-substrate fermentation (Fig. 4b) was absent here and $n$-butanol was produced at an early stage in all the co-substrate fermentations (Figs. 5, 6 and 7).

As can be seen in Fig. 5 with a glucose-to-glycerol ratio of $1: 4$, immediately after glucose consumption, the glycerol consumption rate decreased from 4.3 to $2.3 \mathrm{~g} / \mathrm{L} \times \mathrm{h}$ and lasted for
$5 \mathrm{~h}$ and then stopped completely. A maximum $n$-butanol concentration of $11 \mathrm{~g} / \mathrm{L}$ was obtained. On the other hand, in experiments with a glucose-to-glycerol ratio of 4:1 (Fig. 6), and after the onset of glycerol limitation, the $n$-butanol productivity decreased from 0.76 to $0.4 \mathrm{~g} / \mathrm{L} \times \mathrm{h}$, and a maximum $n$-butanol concentration of $12 \mathrm{~g} / \mathrm{L}$ was obtained. At this
Fig. 4 Product formation by C. pasteurianum during growth on glucose in a $\mathrm{pH}$-controlled batch culture and their productivities

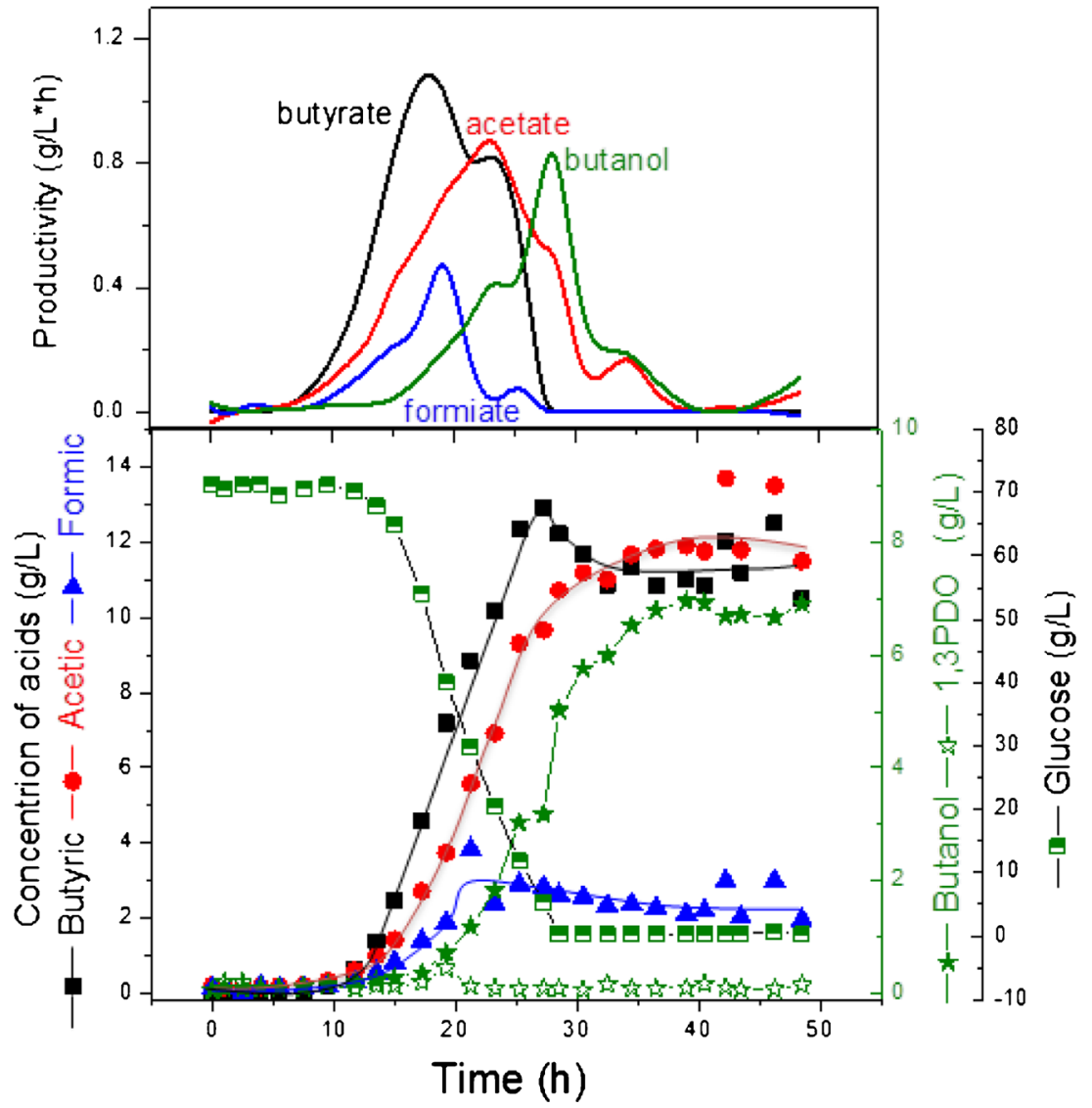




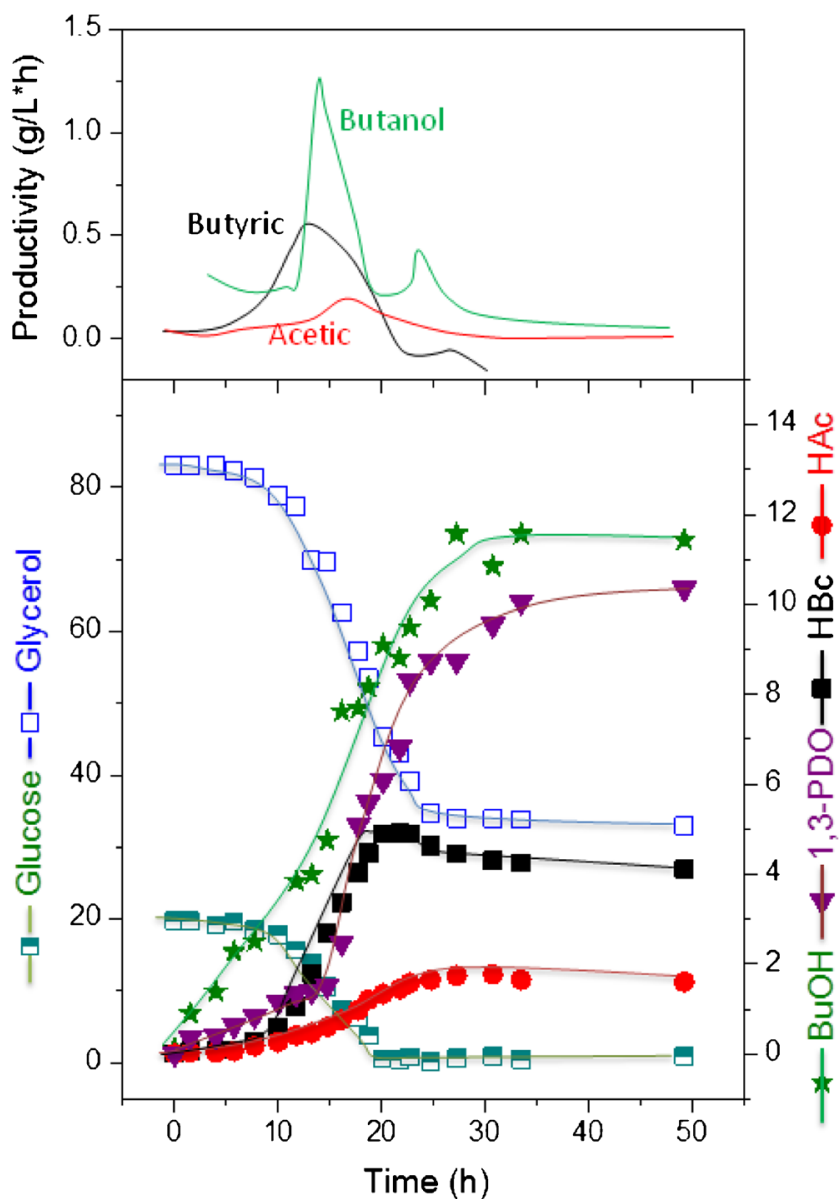

Fig. 5 Product formation by C. pasteurianum DSMZ 525 during growth on glucose/glycerol blend in a ratio of 1:4 in a pH-controlled batch culture and productivities of the metabolites

glucose-to-glycerol ratio, most of the glucose utilized was directed to acids, the glucose consumption rate remained unaffected by the limitation of glycerol and the cells utilized glucose till the end of the experiment.

In the fermentation with glucose-to-glycerol ratio of 1:1, where no limitation of either substrate was observed, the maximum $n$-butanol concentration was obtained and recorded $21 \mathrm{~g} / \mathrm{L}$ (Fig. 7). This is the highest concentration ever reached in literature of $n$-butanol with batch culture and without in situ removal of butanol. The maximum productivity of $n$-butanol recorded a value of $0.9 \mathrm{~g} / \mathrm{L} \times \mathrm{h}$. A comparison of the biomass formation as affected by different substrate limitation in the co-substrate fermentation is depicted in Fig. 8.

Co-substrate fermentation using spruce $\mathrm{BH}$ and glycerol

Generally, substrates are a major proportion of product costs. Hence, to increase the economical feasibility of $n$-butanol production, we used $\mathrm{BH}$ instead of pure glucose in this experiment. The co-substrate fermentation was performed using diluted spruce BH. The hydrolysate was autoclaved separately and added to the sterile medium containing glycerol. Table 1

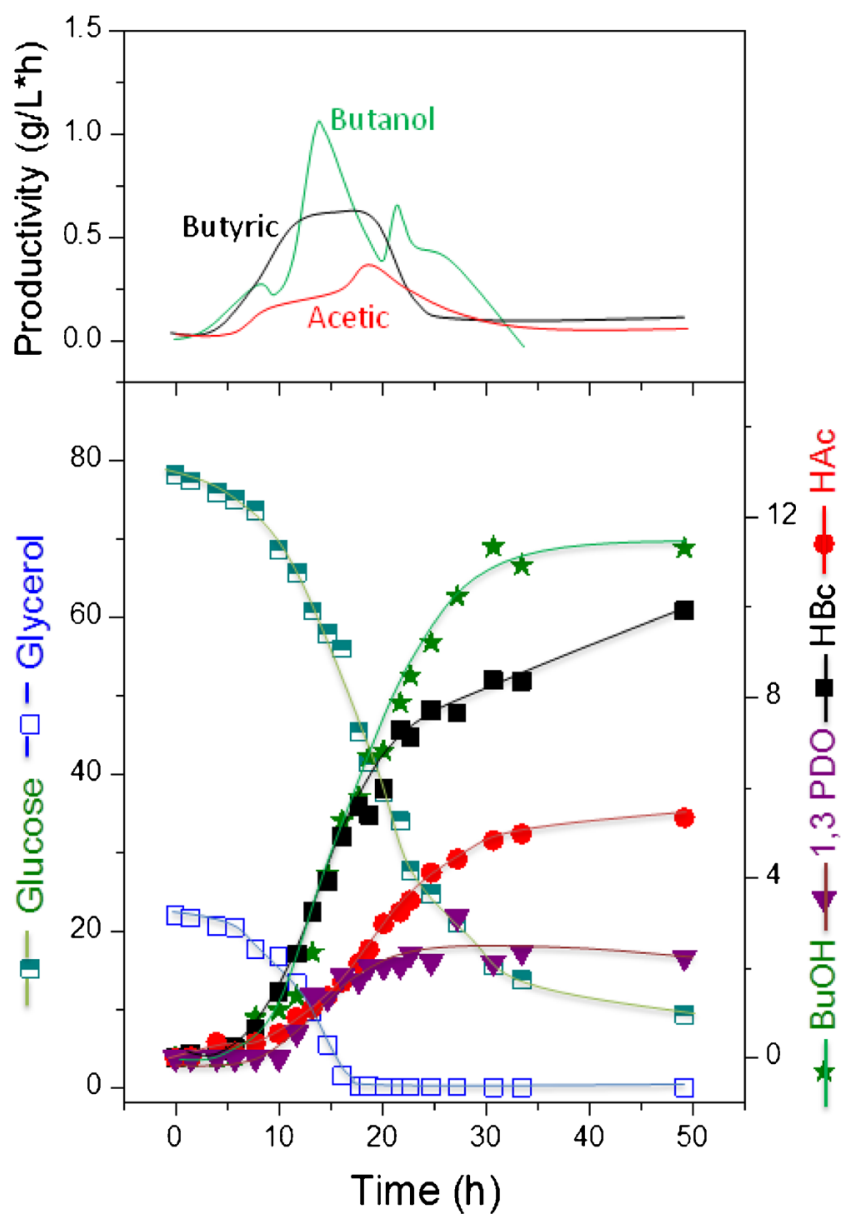

Fig. 6 Major product formation by $C$. pasteurianum during growth on glucose/glycerol blend in a ratio of 4:1 in a $\mathrm{pH}$-controlled batch culture and productivities of the metabolites

summarizes the results obtained with the hydrolysate in a ratio of 1:1 with glycerol and the results obtained at different ratios with pure glucose. A maximum $n$-butanol titer of $17 \mathrm{~g} / \mathrm{L}$ was reached in the mixed substrate fermentation with $\mathrm{BH}$. Remarkably, in the mixed substrate fermentation with $\mathrm{BH}$ and following the same trends showed in Fig. 8, the glycerol consumption stopped at the onset of glucose limitation.

\section{Discussion}

Despite the high potential of C. pasteurianum for the production of $n$-butanol (Biebl 2001; Malaviya et al. 2012; Khanna et al. 2013a, b), only a few publications have dealt with the optimization of $n$-butanol production with this microorganism. Previously, with C. pasteurianum, instability and great variation in the formation of the two major products 1,3-PDO and butanol was revealed after growth on glycerol (Biebl 2001). The author showed that under almost the same conditions, the strain could produce 1.3-PDO or $n$-butanol as the major product. Recently, many authors have optimized the 


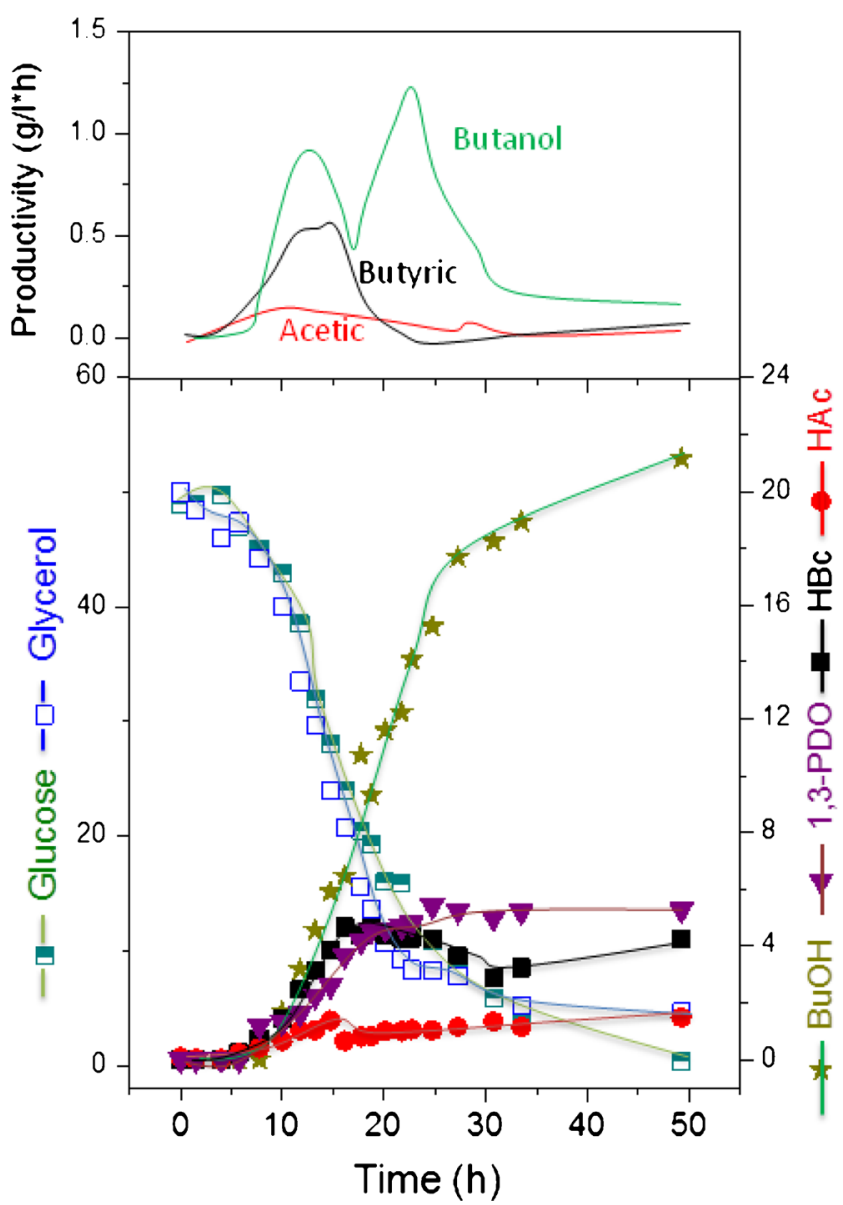

Fig. 7 Time dependent fermentation profile of C. pasteurianum DSMZ 525 growing on glucose/glycerol blend in a ratio of 1:1 in a pH-controlled batch culture

cultivation conditions to favour the production of one of these two products (Moon et al. 2011; Khanna et al. 2013a, b). Obviously, both products are essential for the balance of the redox within the cell.

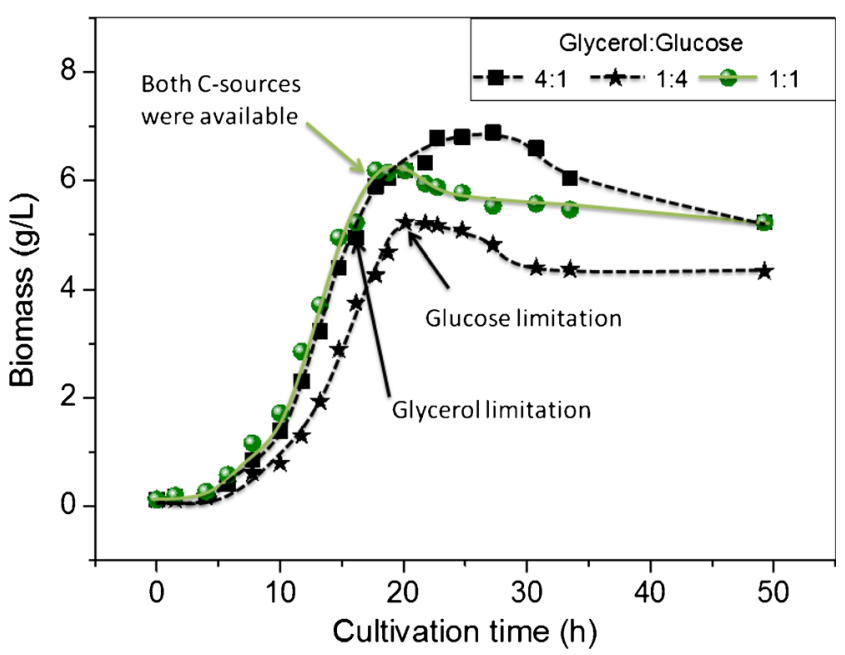

Fig. 8 Biomass formation as affected by carbon source limitation in the mixed substrate fermentation
Previously, it was shown that acetate and butyrate addition triggered the pathway in C. acetobutylicum to shift from acidogenesis to solventogenesis ( $\mathrm{Li}$ et al. 2011). Therefore, we investigated the effects of addition of different cosubstrates on the production of $n$-butanol and 1,3-PDO by C. pasteurianum DSMZ 525. At a constant initial $\mathrm{pH}$ of 7, in anaerobic bottles, the results obtained, with respect to acid addition, were in agreement with the work done by Li et al. (2011) for C. acetobutylicum and by Kao et al. (2012) for C. pasteurianum $\mathrm{CH} 4$ strain. The specificity of $n$-butanol formation by $C$. pasteurianum DSMZ 525 was also enhanced significantly by the addition of acids (Fig. 1). It should be stressed here, that in C. pasteurianum grown on glycerol, where both acid and solvent formation occurs simultaneously, the positive effect of acid addition remains unclear (Figs. 1 and 2). On the other hand, in $\mathrm{pH}$-controlled reactors at $\mathrm{pH}=6$, the addition of butyrate did not enhance $n$-butanol production significantly (Fig. 2). Since $\mathrm{pH}$ is known to be a crucial factor affecting the performance of ABE fermentation by Clostridia (Dabrock et al. 1992; Haus et al. 2011; Moon et al. 2011; Malaviya et al. 2012; Khanna et al. 2013a; Millat et al. 2013), the variation of $\mathrm{pH}$ in anaerobic bottles may explain such difference. In the anaerobic bottle experiments shown in Fig. 1, the buffering agent $\left(\mathrm{CaCO}_{3}\right)$ is not sufficient to stabilize the $\mathrm{pH}$, and 'acid crash', a phenomenon occasionally occurs in pH-uncontrolled batch fermentations, will indeed affect the growth and product formation (Maddox et al. 2000). Indeed, the varied $\mathrm{pH}$ and the accumulation of undissociated acids in broths may then explain the premature cessation of metabolism and glycerol consumption in batch cultures. Additionally, the pressure created in such anaerobic bottles resulted in the dissolution of the produced gas into the medium, and therefore adding unstudied factors inside the anaerobic bottles. For example, it was shown that culture grown for 4 days in standard bottles with pressurized cultivation consumed $15 \mathrm{~g} / \mathrm{L}$ glycerol compared to $44 \mathrm{~g} / \mathrm{L}$ in bottles with regular pressure release. Moreover, $n$-butanol production increased significantly in the unpressurized bottles and reached $6.7 \mathrm{~g} / \mathrm{L}$ compared to $1.6 \mathrm{~g} / \mathrm{L}$ in standard bottle with pressurized cultivation.

In the $\mathrm{pH}$-controlled experiments, and since butyric acid was added at the same concentration, the effect of the undissociated acids were shown to be dependent on the growth phase. This explains the diminished growth rate or even the inhibition of growth after the addition of butyric acid at a fixed $\mathrm{pH}$ value, or the extended lag period or growth failure if butyric acid was added at the beginning at $\mathrm{pH}$ set value of 6 or 5.5, respectively. Interestingly and as shown in Figs. 1 and 3 , butyric acid addition resulted in a higher butanol/1,3-PDO ratio. Acetone was never detected in samples taken at the experiment end. This fact excludes the possible redirection of butyrate to $n$-butanol pathway by the CoA-transferase linked to acetone production. Previously, it was reported that 
Table 1 Mono- versus co-substrate fermentations using C. pasteurianum DSMZ 525

\begin{tabular}{|c|c|c|c|c|c|c|c|c|}
\hline \multirow[t]{2}{*}{ Mono/mixed substrate } & \multicolumn{5}{|c|}{ Concentration $(\mathrm{g} / \mathrm{L})$} & \multicolumn{2}{|c|}{ Yield $\left(g / g_{\mathrm{C} 3+\mathrm{C} 6}\right)$} & \multirow{2}{*}{$\begin{array}{l}\text { Overall butanol } \\
\text { productivity }(\mathrm{g} / \mathrm{L} \times \mathrm{h})\end{array}$} \\
\hline & Butyric acid & Acetic acid & 1,3-PDO & Butanol & Biomass & Butanol & 1,3-PDO & \\
\hline \multicolumn{9}{|l|}{ Mono-substrate } \\
\hline Glucose & 10.5 & 11.9 & 0.0 & 6.9 & 13.2 & 0.1 & 0 & 0.21 \\
\hline $\mathrm{BH}$ & 11.7 & 15.5 & 0.0 & 6.8 & 8.5 & 0.1 & 0 & 0.20 \\
\hline Glycerol & 0.1 & 0.4 & 5.3 & 13.9 & 3.2 & 0.25 & 0.1 & 0.68 \\
\hline \multicolumn{9}{|l|}{ Mixed substrates } \\
\hline \multicolumn{9}{|l|}{ Glu to Gly } \\
\hline $4: 1$ & 9.9 & 5.3 & 2.2 & 11.3 & 6.8 & 0.13 & 0.03 & 0.41 \\
\hline $1: 1$ & 4.2 & 1.5 & 5.2 & 21.1 & 6.1 & 0.23 & 0.06 & 0.69 \\
\hline $1: 4$ & 4.11 & 1.6 & 10.3 & 11.4 & 5.2 & 0.17 & 0.15 & 0.37 \\
\hline \multicolumn{9}{|l|}{ Mixed substrates } \\
\hline \multicolumn{9}{|l|}{ BH to Gly } \\
\hline $1: 1$ & 4.1 & 4.2 & 1.8 & 17.4 & 6.1 & 0.2 & 0.02 & 0.62 \\
\hline
\end{tabular}

BH biomass hydrolysate, Glu glucose, Gly glycerol

iron excess conditions enhanced the butanol/1,3-PDO ratio significantly in C. pasteurianum (Dabrock et al. 1992; Jensen et al. 2012a). Moreover, in C. pasteurianum batch culture controlled at $\mathrm{pH} 6$, a $\mathrm{pH}$ shift to the acidic range at the mid logarithmic phase stopped 1,3-PDO formation but enhanced $n$-butanol productivity significantly (data not shown). Still the exact mechanism of the positive effect of butyric acid addition on $n$-butanol production in C. pasteurianum, especially in $\mathrm{pH}$ uncontrolled cultures, is not known and need more investigation.

Triggering bacterial own acid production through glucose addition, however, enhanced biomass and $n$-butanol production significantly. Using glucose as a co-substrate, the butanol/ 1,3-PDO ratio increased significantly. In fact, the 1,3-PDO concentration increased in C. pasteurianum cultures with the increase in the glycerol moieties of the co-substrate fermentation (Table 1). On the other hand, acid production increased significantly with the increase in the glucose moieties of the co-substrate fermentation (Table 1). Acetate and butyrate are produced from acetyl-CoA and butyryl-CoA, respectively, by means of two analogous steps, which result in the generation of one ATP molecule per each reaction, and this explain the increase of biomass observed with the increase in acid production in the co-substrate fermentation (Table 1).

For $n$-butanol production by C. pasteurianum DSMZ 525, the limitation of either substrate during the course of fermentation should be avoided (Fig. 7). Experiments with glucose or glycerol limitation showed a decrease in the $n$-butanol production significantly (Figs. 5 and 6). The effect of mixed substrate fermentation on $n$-butanol production appears to be strain dependent. In $C$. acetobutylicum, $n$-butanol productivity was much lower in mixed substrate fermentation than on glucose, and a maximum productivity of $0.42 \mathrm{~g} / \mathrm{L} \times \mathrm{h}$ compared to $0.9 \mathrm{~g} / \mathrm{L} \times \mathrm{h}$ was reported on mixed or monosubstrate fermentation, respectively (Andrade and Vaconcelos 2003). On the other hand, C. pasteurianum strain CH4 produced $13.2 \mathrm{~g} / \mathrm{L} n$-butanol with a productivity of $0.19 \mathrm{~g} / \mathrm{L} \times \mathrm{h}$ in co-substrate fermentation compared to $11 \mathrm{~g} / \mathrm{L}$ and $0.14 \mathrm{~g} / \mathrm{L} \times \mathrm{h}$ on glycerol (Kao et al. 2012).

To compete effectively with petrochemical-derived butanol, the use of lignocellulosic biomass as a substrate has a great potential. Compared to pure glucose, the growth rate on BH is slightly slower $\left(0.2\right.$ compared to $0.25 \mathrm{~h}^{-1}$ with pure glucose). The maximum $n$-butanol productivities were almost similar in glucose or BH in mono-substrate or mixed substrate fermentation with glycerol (Table 1). Interestingly, in experiments with 1:1 ratio of BH to glycerol, glucose was consumed with a rate of $3.2 \mathrm{~g} / \mathrm{L} \times \mathrm{h}$ compared to a glycerol consumption rate of $2.2 \mathrm{~g} / \mathrm{L} \times \mathrm{h}$. In agreement with the results shown in Fig. 5, with low glucose-to-glycerol ratio, inhibition of glycerol utilization was noticed shortly after glucose limitation.

Although C. pasteurianum can utilize either glycerol or glucose separately as a sole carbon and energy source, the observed inhibition of glycerol utilization after the exhaustion of glucose is still not understood in the mixed substrate fermentation by $C$. pasteurianum, and is therefore crucial if an optimization of $n$-butanol production is aimed. The growth of the bacterium was also stopped after glucose limitation (Fig. 8). This was not found when glycerol was limited in fermentation with a high glucose/glycerol ratio (Fig. 8). One explanation for this may be the improved acclimation of C. pasteurianum cells to $n$-butanol stress in the presence of glucose, which resulted in a higher resistance to $n$-butanol toxicity. Indeed, the tolerance of the bacteria to higher $n$ butanol concentrations was significantly enhanced when both substrates were simultaneously fermented in anaerobic bottles 
compared to mono-substrate fermentation with glycerol (data not shown). The production of acids during glucose utilization plays an important role in maintaining the redox balance of the cells by oxidizing NADH to NAD + . With mixed substrate fermentation, in C. butyricum (Saint-Amans et al. 2001) and in C. acetobutylicum (Vasconcelos et al. 1994), it was shown that most of the reduced ferrodoxin produced by the pyruvate ferrodoxin oxidoreductase was used to generate NADH leading to low hydrogen production. Moreover, the improved $n$ butanol tolerance of the cells might be associated with the energetic status of the cell in the presence of glucose. Acid production parallels the energy production necessary for cell viability and homeostasis at high $n$-butanol concentration. This may explain the enhancement of culture stabilities in C. acetobutylicum and prevention of cell degeneration in the mixed substrate fermentation (Andrade and Vaconcelos 2003). Although a number of possible mechanisms may account for this, further work is required to determine the underlying mechanism(s).

Acknowledgments This work was financially supported by the European Union Seventh Framework Program (FP7/2007-2013) under grant agreement no. 241718 EuroBioRef

Open Access This article is distributed under the terms of the Creative Commons Attribution License which permits any use, distribution, and reproduction in any medium, provided the original author(s) and the source are credited.

\section{References}

Andrade JC, Vaconcelos I (2003) Continuous cultures of Clostridium acetobutylicum: culture stability and low-grade glycerol utilisation. Biotechnol Lett 25:121-125

Biebl H (2001) Fermentation of glycerol by Clostridium pasteurianumbatch and continuous culture studies. J Ind Microbiol Biotechnol 27: $18-26$

Dabrock B, Bahl H, Gottschalk G (1992) Parameters affecting solvent production by Clostridium pasteurianum. Appl Environ Microbiol 58:1233-1239

Garcia V, Päkkilä J, Ojamo H, Muurinen E, Keiski RL (2011) Challenges in biobutanol production: how to improve the efficiency? Renew Sust Energ Rev 15:964-980

Haus S, Jabbari S, Millat T, Janssen H, Fischer RJ, Bahl H, King JR, Wolkenhauer O (2011) A systems biology approach to investigate the effect of $\mathrm{pH}$-induced gene regulation on solvent production by Clostridium acetobutylicum in continuous culture. BMC Syst Biol 5:10

Jang YS, Lee JY, Lee J, Park JH, Im JA, Eom MH, Lee J, Lee SH, Song H, Cho JH, Seung dY, Lee SY (2012) Enhanced N-butanol production obtained by reinforcing the direct butanol-forming route in Clostridium acetobutylicum. MBio 3(5):1-9

Jensen TO, Kvist T, Mikkelsen MJ, Christensen PV, Westermann P (2012a) Fermentation of crude glycerol from biodiesel production by Clostridium pasteurianum. J Ind Microbiol Biotechnol 39:709717

Jensen TO, Kvist T, Mikkelsen MJ, Westermann P (2012b) Production of 1,3-PDO and butanol by a mutant strain of Clostridium pasteurianum with increased tolerance towards crude glycerol. AMB Express 2(1):44

Jesse TW, Ezeji TC, Qureshi N, Blaschek HP (2002) Production of butanol from starch-based waste packing peanuts and agricultural waste. J Ind Microbiol Biotechnol 29:117-123

Kao WC, Lin DS, Cheng CL, Chen BY, Lin CY, Chang JS (2012) Enhancing butanol production with Clostridium pasteurianum $\mathrm{CH} 4$ using sequential glucose-glycerol addition and simultaneous dualsubstrate cultivation strategies. Bioresour Technol 135:324-330

Khanna S, Goyal A, Moholkar VS (2013a) Effect of fermentation parameters on bio-alcohols production from glycerol using immobilized Clostridium pasteurianum: an optimization study. Prep Biochem Biotechnol 43:828-847

Khanna S, Ranjana A, Goyala A, Moholkar VS (2013b) Medium optimization for mixed alcohols production by glycerol utilizing immobilized Clostridium pasteurianum MTCC 116. Chem Biochem Eng Q 23:319-325

Lee J, Jang YS, Choi SJ, Im JA, Song H, Cho JH, Seung dY, Papoutsakis ET, Bennett GN, Lee SY (2012) Metabolic engineering of Clostridium acetobutylicum ATCC 824 for isopropanol-butanolethanol fermentation. Appl Environ Microbiol 78:1416-1423

Li RD, Li YY, Lu LY, Ren C, Li YX, Liu L (2011) An improved kinetic model for the acetone-butanol-ethanol pathway of Clostridium acetobutylicum and model-based perturbation analysis. BMC Syst Biol 5(Suppl 1):S12

Liu XB, Gu QY, Yu XB (2013) Repetitive domestication to enhance butanol tolerance and production in Clostridium acetobutylicum through artificial simulation of bio-evolution. Bioresour Technol 130:638-643

Maddox IS, Steiner E, Hirsch S, Wessner S, Gutierrez NA, Gapes JR, Schuster KC (2000) The cause of "acid-crash" and "acidogenic fermentations" during the batch acetone-butanol-ethanol (ABE-) fermentation process. J Mol Microbiol Biotechnol 2:95-100

Malaviya A, Jang YS, Lee SY (2012) Continuous butanol production with reduced byproducts formation from glycerol by a hyper producing mutant of Clostridium pasteurianum. Appl Microbiol Biotechnol 93:1485-1494

Millat T, Janssen H, Thorn GJ, King JR, Bahl H, Fischer RJ, Wolkenhauer O (2013) A shift in the dominant phenotype governs the $\mathrm{pH}$-induced metabolic switch of Clostridium acetobutylicumin phosphate-limited continuous cultures. Appl Microbiol Biotechnol 97:6451-6466

Moon C, Lee CH, Sang BI, Um Y (2011) Optimization of medium compositions favoring butanol and 1,3-propanediol production from glycerol by Clostridium pasteurianum. Bioresour Technol 102: 10561-10568

Patakova P, Linhova M, Rychtera M, Paulova L, Melzoch K (2013) Novel and neglected issues of acetone-butanol-ethanol (ABE) fermentation by clostridia: Clostridium metabolic diversity, tools for process mapping and continuous fermentation systems. Biotechnol Adv 31:58-67

Qureshi N, Li XL, Hughes S, Saha BC, Cotta MA (2006) Butanol production from corn fiber xylan using Clostridium acetobutylicum. Biotechnol Prog 22:673-680

Qureshi N, Saha BC, Cotta MA (2007) Butanol production from wheat straw hydrolysate using Clostridium beijerinckii. Bioprocess Biosyst Eng 30:419-427

Qureshi N, Ezeji TC, Ebener J, Dien BS, Cotta MA, Blaschek HP (2008) Butanol production by Clostridium beijerinckii. Part I: use of acid and enzyme hydrolyzed corn fiber. Bioresour Technol 99:5915-5922

Saint-Amans S, Girbal L, Andrade JC, Ahrens K, Soucaille P (2001) Regulation of carbon and electron flow in Clostridium butyricum VPI 3266 grown on glucose-glycerol mixtures. J Bacteriol 183: $1748-1754$

Tracy BP (2012) Improving butanol fermentation to enter the advanced biofuel market. MBio 3(6) doi:10.1128/mBio.00518-12 
Vandecasteele JP, Marchal R (1993) Les bactéries solvantogènes du genre Clostridium. In: Leveau JY, Bouix M (eds) Microbiologie Industrielle. Les Micro-Organismes d'Intérêt Industriel. Tec \& Doc Lavoisier, Paris, pp 489-537

Vasconcelos I, Girbal L, Soucaille P (1994) Regulation of carbon and electron flow in Clostridium acetobutylicum grown in chemostat culture at neutral $\mathrm{pH}$ on mixtures of glucose and glycerol. J Bacteriol 176:1443-1450

Zverlov VV, Berezina O, Velikodvorskaya GA, Schwarz WH (2006)

Bacterial acetone and butanol production by industrial fermentation in the Soviet Union: use of hydrolyzed agricultural waste for biorefinery. Appl Microbiol Biotechnol 71:587-597 